\title{
Review Article \\ Residual Risk of Hepatitis-B-Infected Blood Donations: Estimation Methods and Perspectives
}

\author{
Emil Kupek \\ Department of Public Health/CCS, Universidade Federal de Santa Catarina, 88040-900 Florianopolis, SC, Brazil \\ Correspondence should be addressed to Emil Kupek; kupek@ccs.ufsc.br
}

Received 11 February 2013; Accepted 19 April 2013

Academic Editors: Y.-H. Gan, V. Konjufca, and Y. Madec

Copyright (C) 2013 Emil Kupek. This is an open access article distributed under the Creative Commons Attribution License, which permits unrestricted use, distribution, and reproduction in any medium, provided the original work is properly cited.

\begin{abstract}
Despite a considerable reduction of the risk of HBV-infected blood donation entering blood supply (residual risk) due to improved screening by HBV NAT in the developed countries, the bulk of the people with HBV living in the developing countries still needs to be screened by serologic tests such as HBsAg and anti-HBc. Many of these countries lack resources for implementing NAT and are likely to remain so in the next decade or longer, thus depending on the HBV residual risk monitoring based on serologic testing and corresponding estimation methods. This paper reviews main HBV residual risk findings worldwide and the methods based on serology used for their calculation with repeat donors, as well as their extension to the first-time donors. Two artificial datasets with high $(4.36 \%)$ and low $(0.48 \%) \mathrm{HBV}$ prevalence were generated to test the performance of five methods: the original incidence/window-period model based solely on HBsAg, its modification by Soldan in 2003, the Müller-Breitkreutz model, the HBsAg yield model, and its extension to include anti-HBc seroconversions within a year. The last model was closest to the true values of residual risk and had smallest variation of the estimates in both high and low prevalence data. It may be used for residual risk evaluation in relatively small samples, such as regional blood banks data.
\end{abstract}

\section{Introduction}

The consequences of infection by Hepatitis B virus (HBV) remain among the most devastating ones for an immunopreventable disease, particularly in the developing countries. The World Health Organization (WHO) estimates of the disease burden worldwide are widely cited in the literature. A decade ago, three quarters of the world population lived in the areas of high HBV prevalence [1]. Even the countries with universal child vaccination against $\mathrm{HBV}$ and advanced blood screening technology such as the USA still report a sizable HBV burden [2]. However, partitioning of this burden within countries and their regions is less well known as many of the high-incidence countries lack adequate epidemiological surveillance and systematic evaluation of the HBV impact on the health of the population. For example, even a simplified calculation of HBV morbidity and mortality burden developed by Goldstein and colleagues in 2005 [3] and available via the Centre for Disease Control and Prevention (CDC) website has been rarely used for a systematic country-specific evaluation of the yield of the public health policies. HBV vaccine coverage and incidence reduction over time are most frequently used instead. Although these are important intermediate measures in socalled process evaluation [4], their impact on quality of life and mortality, often delayed for decades due to rather slow progression towards severe diseases such as liver cancer or cirrhosis, may be easily missed by the health policy makers. The underestimation of the HBV impact is exacerbated by perceiving other diseases with more immediate adverse effects as more serious by general public and health authorities alike, leading to prioritizing the latter.

The above situation has led to a paradoxal situation where the disease burden of HBV infection which can be prevented by affordable vaccine remains grossly underestimated, even when HBV is one of the principal causes of mortality among infectious diseases. Apart from the relatively low incidence $(<1 \%)$ of fulminant hepatitis $\mathrm{B}$ with high mortality rates, most of the HBV-related deaths are attributed to the endpoint chronic diseases, mainly liver cancer and cirrhosis. In the beginning of this century, the HBV residual risk in Europe was estimated to be the cause of almost $1 \%$ of posttransfusion deaths due to a liver disease, mostly because 
of a fulminant form of the hepatitis B [5]. The shift in the emphasis from infectious to chronic diseases has been largely due to demographic and epidemiologic transition over the past decades, thus contributing to the widespread public perception of HBV as a low-level threat to individual and public health. While this may be reasonable for the developed countries, it is highly unlikely to hold for the developing countries for two reasons. First, many of the latter have started their HBV immunization programs relatively recently, so that large sections of the population remain exposed to HBV. This problem is obviously more serious in the countries where no universal child immunization has yet taken place. Second, high endemicity of HBV is largely concentrated in the developing countries, so its impact is likely to persist for longer time given the high HBV burden accumulated over time.

It is against this general background of the public health policies to combat HBV that the measures to reduce its transmission by blood transfusion and organ transplantation need to be evaluated. Although serologic screening for HBV had been introduced before HIV pandemic took place, it was the latter that increased the general public perception of the pressing need to improve blood safety. During the decade of 1990, all developed and the majority of the developing countries have improved HIV screening with p24 component added to the enzyme immunoassays. The second half of the decade was marked by the development of nucleic acid testing (NAT) technology in blood bank setting, mainly for $\mathrm{HIV}$ and hepatitis C virus (HCV), but also for HBV in the developed countries [6, 7]. As public risk perception of transfusional risk sets high standards for the HIV, it eventually elevated blood safety standards for other diseases transmissible by blood transfusion, including HBV. The latter was highly motivated by the concern about occult hepatitis $\mathrm{B}$ infection (OBI) and its impact on blood transfusion safety. As detection of OBI requires very sensitive NAT, this research agenda has attracted much interest in the recent years in the technologically advanced countries. Other countries, many of them with high HBV prevalence, mainly rely on serologic HBV markers to deal with the OBI threat to blood safety.

NAT era has opened the possibility to directly verify the number of NAT-positive and serology-negative blood donors, denominated as "NAT yield", and to calculate its costutility with greater precision $[7,8]$. On the other hand, this important diagnostic advance has furthered the sharp divide in blood safety standards between the developed and the developing nations. The purpose of this work is to review the methods for residual risk estimation based on serologic HBV markers, making these methods easier to implement in large parts of the world where the HBV NAT is unlikely to be used in the near future. As this estimation includes HBV incidence, it is also of great importance to evaluate its burden and health policies to reduce it more realistically.

The text that follows reviews some major issues in the socalled residual risk estimation for HBV, which refers to the risk of HBV-infected donation entering the blood supply, trying to show geographical diversity and common grounds of worldwide experiences in dealing with this issue. It also provides an example of how to calculate the risk estimates with a variety of methods and shows their performance using two artificial data sets: one with high and the other with low HBV prevalence. Particular attention is given to the methods suitable for relatively small samples (of the order of 100.000) in low versus high HBV prevalence settings, in order to encourage their use for systematic risk monitoring in regional blood banks.

\section{An Overview of the HBV Residual Risk Reports Worldwide}

This section reviews the reports on the HBV residual risk from all over the world. As the majority of the reports referred to the developed countries, a separate review was made regarding the level of economic development. By and large, this division also corresponds to the levels of HBV prevalence; important exceptions to the rule are also reviewed. An effort was made to organize the major results by continents, countries, and sometimes even by regions within a country when such data were available. The testing algorithms for HBV prevalence were specified in most cases.

2.1. Developed Countries. The USA have been leading the residual risk research since the REDS study provided its initial impulse [9]. In the beginning of the 2000 decade, residual risk and NAT yield for HIV, $\mathrm{HCV}$, and $\mathrm{HBV}$ were mainly estimated by the incidence/window-period models (see Section 3 of the paper for a review of this and other models). For the period 1995-2001, the repeat donors HBV incidence was estimated by HBsAg (surface HBV antigen) alone at 1.27 per 100.000 , with this figure twice as high for the first-time donors [10]. Another study found that a sudden influx of the first-time donors almost tripled the proportion of HBsAg reactive tests from $0.1 \%$ to $0.3 \%$, thus increasing the HBV residual risk from $1: 170.000$ to $1: 140.000$ [11]. In 2001, cost-effectiveness of the triplex NAT (HIV, HCV, and HBV) was thought poor, with the cost varying in the range of $U \$$ 3.5-4.3 million to prevent one transfusion-transmitted HBV infection [12]. Although the HBV residual risk was relatively high $(1: 205.000)$ in the beginning of the 2000 decade, other infections transmissible by blood transfusion, such as variant Creutzfeld-Jacobs disease, West Nile encephalitis, malaria, Chagas, severe acute respiratory syndrome, and babesiosis, were pointed out as targets for the residual risk research [9, $13,14]$. For example, about 100 West-Nile-infected donations were estimated removed from the USA blood supply in 2003 [15]. Using revised HBV window period of 30-38 days, a marked reduction in the $\mathrm{HBV}$ residual risk was calculated from $1: 86.000-1: 110.000$ in $1997-99$ to $1: 280.000-1: 355.000$ in 2006-8 [16]. The most recent estimates of the HBV residual risk in the USA were approximately $1: 300.000$ [17].

In Canada, HBV incidence and residual risk were estimated at 12.4 and 1.4 per 100.000 donors, respectively [18]. In 2005, a study showed that anti-HBc (core HBV antibody) screening yielded between $1: 17.800$ and $1: 69.300 \mathrm{HBV}$ infections among HBsAg-negative and HBV-DNA-positive donors [19]. The HBV residual risk was estimated at 1:153.000 for the first half of the 2000 decade [20]. A case-control 
study covering the period between 1997 and 2006 showed that immigration from highly endemic areas was a major risk factor for HBV infection in the first-time donors [21].

In Europe, a mathematical model of residual risk and NAT yield for HIV, HCV, and HBV projected the yield of 1.2 per million by ID (individual donation) NAT for the year 1997, considered a rather small gain [22]. Another mathematical modeling of the cost per life-year gained with enhanced sensitivity HBsAg tests and HBV ID NAT was evaluated at 0.73 and 5.8 million euros $\mathrm{p} / 10$ million donations, respectively, for Europe in year 2000 [5]. The former option was deemed acceptable and the latter too costly at the time. After the introduction of NAT screening for the EU countries, more precise cost-effectiveness measures such as ICER (incremental cost-effectiveness ratio) per quality adjusted life-year became available, showing a value of 303.000 euros and 519.000 euros for HBV MP (minipool) NAT and ID NAT, respectively, for the Netherlands by the end of the 2010 decade [8]. The former option was thought acceptable and the latter too expensive.

Other European countries produced their HBV residual risk estimates too. In Spain, NAT screening for HIV and HCV was introduced in 1999 and halved residual risk per million from 18.67 to 9.78 during the 1997-2002 period [23]. However, the risk of $\mathrm{HBV}$ transmission by transfusion was estimated at $1: 17.316$ in a cohort study of Spanish blood donor recipients [24].

In Italy, first estimates for the second half of the 1990 decade reported HBV incidence of 10 per 100.000 and associated residual risk of $1: 62.500$ [25]. The residual risk for the 1999-2001 period was estimated at 1:14.286 using incidence/window period and HBV incidence adjusted for the transient nature of HBsAg [26]. In North-Western Italy, the residual risk for OBI was estimated to be about hundred times lower than for the HBsAg preseroconversion window period due [27]. However, despite low infectivity of OBI blood donations, many of its recipients were immunocompromised and therefore more susceptible to HBV. For the whole country, HBV NAT yield between 2001 and 2006 was evaluated at 5.78 per 100.000 donors or $1: 17.301$, largely due to OBI which was detected in $96 \%$ of the yield cases [28]. In the Latium region, HBV NAT yield was $1: 25.021$ over HBsAg, mainly for early WP infections but also for the late phase of resolving $\mathrm{HBV}$ infection, for serologically silent chronic $\mathrm{HBV}$, and for rare HBsAg mutants [29].

The Swiss blood bank estimates 1:115.000 for the HBV residual risk in the first years of the 2000 decade were relatively high [30]. Although adding anti-HBc to routine $\mathrm{HBsAg}$ testing was thought to be cost-effective, with low deferral $(<2 \%)$ of noninfectious donors [31], HBV ID NAT screening was introduced and showed the yield of $1: 200.000$, with OBI yield of $1: 61.000$ and HBsAg preseroconversion windowperiod risk of $1: 153.000$ [32]. Over the period analyzed, a threefold reduction of the HBV residual risk was achieved by ID NAT from $1: 95.000$ to $1: 296.000$.

In Germany, minipool NAT with 96 samples was estimated to yield 1: 600.000 over HBsAg in 1997, with perceived utility of anti-HBc testing in reducing the HBV residual risk [33]. Although NAT for HIV and HCV reduced the residual risk markedly, it was still unclear what it would be for HBV because low viral load could escape MP NAT, with projected yields of $1: 230.000$ by improved serologic screening and 1:620.000 by MP NAT [34]. In the mid 2010 decade, some authors argued that improving the coverage of $\mathrm{HBV}$ vaccine for blood donors would be as effective as MP NAT [35]. At the same time, a marked reduction in $\mathrm{HBV}$ incidence per 100.000 was observed, from 1.0 to 0.4 [36]. With anti-HBc prevalence of $1.8 \%$ and the HBV residual risk of $1: 500.000$, the introduction of a more sensitive test for this marker (PRISM HBCore) was deemed a viable screening option [37]. The HBV MP NAT yield in Germany during the 1997-2005 period was estimated at $1: 360.000$ [38]. Adding anti-HBc in 2005 deferred $1.75 \%$ noninfectious donors, but this might have been reduced to $0.49 \%$ by using HBV ID NAT and antiHBs titer of $100 \mathrm{IU} / \mathrm{L}$ or more as deferral criteria [39]. The same study showed that most commercial anti-HBc kits were shown to be sensitive and reasonably specific. Another study estimated the risk of HBV seroconversion of 0.6 per 100.000 or $1: 166.667$ in year 2007 [40].

In France, NAT for HIV and HCV was introduced in 2001 and yielded one infected case per 200.000 donations in the first decade of its implementation [41]. The HBV residual risk was estimated at $1: 640.000$ for the 1992-2003 period, and the cost-effectiveness of HIV/HCV NAT was thought poor [42]. Before introduction of HBV NAT screening in 2010, the HBV residual risk was calculated as $1: 1,886.792$, with a lookback research confirming only two cases of $\mathrm{HBV}$ transmitted by blood transfusion [43].

In England, the HBV residual risk was hugely reduced from 1:260.000 in 1993 to $1: 8,000.000$ in 2001 [44]. The study used an adapted incidence/window-period model and simulated various parameters to estimate the credible range of the estimates. Similar risk of $1: 7,142.857$ or 0.14 per million donors was reported for the 1996-2003 period for the whole of Great Britain [45]. HBV incidence based on HBsAg IgM was halved between 1996 and 2008, with the first-time donors comprising most of the cases [46].

In Japan, OBI has become a great concern for safety of the blood supply in the last decade. By analyzing repeat-donor repository samples for the 1997-2004 period, HBV ID NAT found $1.08 \%$ reactive samples, $60 \%$ of which had low antiHBs titer and were considered potentially infectious [47]. A prospective study of blood recipients found a high risk of posttransfusion HBV with 1 in 2139 recipients seroconverting [48]. More recently, a study showed that the HBV residual risk per million donations was reduced from 15.2 with MP NAT for 20 samples to 3.9 with ID NAT, thus preventing $75 \%$ of the window period and $85 \%$ of OBI entering the blood supply [49]. In addition, confirmed OBI transmission rate was up from $0.67 \%$ to $1.94 \%$ among donors with low-titre anti-HBc or anti-HBs viremia.

Taiwan is a rare developed country with relatively high HBV prevalence. In 2000, a six-month followup of a cohort of blood recipients screened solely by HBsAg showed posttransfusion transmission rate of 20 per 100.000 confirmed by HBV-DNA-positive results, providing an argument for HBV NAT in highly endemic areas [50]. Another cohort study with the same duration of followup revealed $0.9 \%$ blood 
recipients with acute posttransfusional HBV among those who had not been vaccinated against HBV [51]. This finding confirmed the significance of OBI risk in hyperendemic areas and a large proportion of anti-HBc deferrals among noninfectious donors, reinforcing the advantages of HBV NAT in such areas. HBV NAT yield was estimated at $0.11 \%$ or $1: 909$ and was evaluated as cost-effective in endemic areas [52]. A lookback study based on repository samples found $1.1 \%$ of them with OBI but none of the blood recipients with HBsAg seroconversion or clinical symptoms of posttransfusion HBV [53]. The author hypothesized that previous exposure to HBV, common in hyperendemic areas, might have reduced the seroconversion and posttransfusion risk.

In the Republic of Korea, the HBV residual risk remained stable during the 2000 decade, with $1: 45.896$ in the beginning and $1: 43.666$ by the end of the decade [54]. The first-time donors' HBV incidence was about 20 times higher than in the repeat donors.

The UAE introduced HBV NAT in 2008. Before its introduction, the HBV residual risk per million was estimated at 1.41 as compared to 0.92 during the HBV NAT era [55].

In Australia, the HBV residual risk models produced an estimate of 1:483.000 in the beginning of the 2000 decade, with predicted HBV NAT yield of one in million [56]. The data available at that time were deemed insufficient to decide whether introducing HBV NAT and/or anti-HBc would be cost-effective.

2.2. Developing Countries. Among developing countries, the African continent has shown the most dramatic situation regarding residual risk not only for $\mathrm{HIV}$ but also for $\mathrm{HBV}$. In the Sub-Saharan Africa, about half of the blood donors were deferred because of HBsAg-reactive rapid test result [57]. The rapid tests widely used in Africa were shown to be sensitive for HIV and HCV but missed 3\% of HBV-DNApositive donors detected with 10-sample minipool testing. Mathematical modeling of the $\mathrm{HBV}$ residual risk in the same region used the $\mathrm{WHO}$ and published incidence and prevalence data to arrive at $\mathrm{HBV}$ infection risk by transfusion of $4.3 \%$ [58]. In Senegal, the HBV residual risk was estimated at $1: 1000$ in the first half of the 2010 decade [59]. In Abidjan, the capital of the Ivory Coast, the HBV residual risk was estimated as 1:383 [60], and in Conackry, the capital of Guineé, it reached staggeringly 1:121 [61]. More recently, a pooled analysis of the data from 51 blood banks in 17 African countries showed low sensitivity (75.6\%) of serological HBV testing by HBsAg and anti-HBc due to widespread use of rapid tests [62]. The specificity of the tests was also lower (94.5\%) compared to the developed countries.

South Africa was the first African country to introduce HBV ID NAT screening, thus being able to observe in the first year of its implementation a yield of $1: 36.612$ for $\mathrm{HBV}$ and 1: 5.200 for OBI among HBsAg-positive donors [6]. More recently, the HBV ID NAT yield was estimated more precisely at $1: 19.608$, of which $1: 25.627$ in pre-anti-HBc and $1: 83.473$ in post-anti-HBc window period [7].

In the Middle East, an analysis from Egypt showed that, in highly endemic region with anti-HBc prevalence of $7.8 \%$, adding this marker to routine HBsAg screening of blood donors yielded 0.5\% HBV-DNA-positive test results [67]. Another research showing the utility of this HBV marker for routine screening in hyperendemic areas was realized in Shiraz, Iran, where the anti-HBc yield reached $6.55 \%$ and that of HBV DNA testing $12.2 \%$ among HBsAg-negative blood donors [68]. On the other hand, this yield was shown to generate a very high discard of likely noninfectious blood donors in Turkey as $99 \%$ of the yield cases were HBV DNA negative [69]. Similar concern was raised in New Delhi where almost $20 \%$ of HBsAg-negative donors were reactive to anti$\mathrm{HBc}$ and $37 \%$ of these tested anti-HBs negative but $41.4 \%$ had anti-HBs titer exceeding $100 \mathrm{UI} / \mathrm{L}$, considered protective against HBV infection [70].

In China, residual risk of 1:17.501 was calculated in Shenzhen, with predicted yield per million donors of 6.9 with more sensitive HBsAg tests, compared to 9.5 for MP NAT and 28.3 for IDNAT [71]. For the whole of China in 2008 and 2009, the HBV ID NAT yield was estimated via incidence/window period at $1: 10.555$ overall, $1: 1.104$ among blood donors with elevated levels of ALT and 1:1.509 for OBI [72]. Under these conditions, MP NAT with 4-16 samples would miss $43 \%-79 \%$ of the HBV ID NAT yield, confirming the effectiveness of the latter as opposed to low utility of elevated ALT for screening purposes in hyperendemic areas.

In Latin America, Brazil has been the leading country in residual risk research, including the $\mathrm{HBV}$-related one. The first didactic introduction of the incidence/window-period model and the residual risk calculation appeared in 1998 [73], followed by a report on significant risk reduction in Santa Catarina state during the 1990 decade [74]. Nevertheless, the $\mathrm{HBV}$ incidence was approximately 300 per 100.000 personyears and corresponding residual risk close to $1: 14.000$, based on the standalone HBsAg method [63]. In addition, the HBV residual risk increased in the first two years of the 2000 decade before resuming a downward trend initiated in the previous decade [75]. This transient upsurge in residual risk was likely the result of HIV test seeking among blood donors, suggested by a significant increase of HIV residual risk over the same period [75]. Another Brazilian study from São Paulo also found evidence of HIV test seeking [76] which was likely to elevate the HBV residual risk as well, given that risky sexual behavior plays a role in the transmission of both viruses in the population. In a Brazilian state with high HBV prevalence areas, the HBV residual risk for the period 1998-2002 was estimated at $1: 10.700$ [77].

\section{Methods for Estimating the HBV Residual Risk}

The Retroviral Epidemiology Donor Study (REDS) has extensively used the incidence/window-period model [63, 78, 79] in the second half of the 1990 decade to estimate the risk of an infected donation entering the blood supply despite negative results of the serologic screening. The risk became known as "residual risk" and was calculated as a product of two independent probabilities: (a) the probability of a donor being infected during the study period, that is, the incidence of a viral infection in the donor population, and (b) the probability of detecting an infectious donation by available 
serologic markers, which tends to zero in the early phase of infection when serologic screening cannot detect specific viral antigens or antibodies, known as immunologic window period $[63,78]$. This approach has been widely applied to $\mathrm{HIV}, \mathrm{HCV}$, and HBV, with some adjustments in the latter case. In the beginning of the 2000 decade, it became an internationally accepted method, applied in various countries [80].

A synthesis of the methods for calculating the HBV residual risk based on routinely used serological markers $\mathrm{HBsAg}$ and/or anti-HBc (IgG + IgM) is presented (Table 1). Other methods using anti-HBc IgM $[45,81]$ or anti-HBe [81] are not considered here as these are mainly research driven and unlikely to be used for routine residual risk monitoring in blood bank setting in the near future.

The following section reviews main models proposed to estimate the HBV RR.

3.1. The Standalone HBsAg. This method is based solely on HBsAg screening and is restricted to repeat blood donors. It includes an adjustment proposed by Korelitz and colleagues [63] that takes into account the transient nature of the marker by dividing its average duration (63 days for the second generation EIA, 77 days for ChLIA|PRISM) [82-84] by the length of the average interdonation interval (IDI) among HBsAg seroconverting repeat donors. The seroconversion is defined as the first positive test result after the last negative result, and the time between the two makes the IDI in question. Over time, more stringent case definitions have been adopted, such as repeatedly positive serologic test results after the first one, sample to cutoff values greater than six, and confirmation of HBV DNA by NAT [65], but the core model remained the same. In addition, this model assumes that $5 \%$ of the repeat donors may be chronic $\mathrm{HBV}$ carriers whose antigens or antibodies are always detected by serologic screening and that $25 \%$ of the donors never produce detectable HBsAg levels due to the primary antibody response [63], thus leading to the following calculation of the probability $(P)$ of detecting an incident $\mathrm{HBV}$ case by HBsAg testing:

$$
P=0.7\left(\frac{\sum s 1}{\operatorname{Mdn}\left(\mathrm{IDI}_{s 1}\right)}\right)+0.05
$$

where $s 1$ and $\mathrm{Mdn}\left(\mathrm{IDI}_{s 1}\right)$ are the number of HBsAg seroconverting repeat donors and their median IDI, respectively. Although most applications so far have used median IDI, mean IDI has been suggested more recently [7].

The adjustment factor for the incidence density (rate) is then $1 / P$, and the incidence is the number of HBsAg seroconverting repeat donors $(s 1)$ divided by all the repeat donor person-time at risk ( IDI $_{\text {ad }}$ ), assuming that the seroconversion occurred at the midpoint of the IDI. Finally, the HBV residual risk is given by multiplying the incidence by its adjustment factor and the WP duration:

$$
\text { Residual risk }=\left(\frac{\sum s 1}{P\left(\sum \mathrm{IDI}_{\mathrm{ad}}-0.5 \sum \mathrm{IDI}_{s 1}\right)}\right) \mathrm{WP}
$$

It is worth noticing that various parameters of the above equation may be highly variable between the donor populations. IDI depends on the donation frequency; the larger the proportion of the repeat donors, the higher the precision of this parameter. Often the definition of repeat donors is restricted to those who donated within last 12 months, whereas those with larger time span between donations are considered "lapsed donors". A variety of social, demographic, and cultural factors influence IDI. Some authors have argued that the assumptions about the incidence adjustment factor may not hold for some donor populations, although its overall impact on the residual risk is likely to be limited [56]. Modifications of the WP model should also include assumed duration of the HBsAg detectability, extended from 63 days for the second generation EIA to 77 days for CHLIA|PRISM [56].

3.2. Müller-Breitkreutz Model. The probability of an infected repeat donor may be estimated by cumulative incidence, that is, the proportion of incident cases among all repeat donors $\left(s 1 / n_{\text {rd }}\right)$, and the probability of an infected WP donation may be estimated by dividing the window duration by the median IDI for HBsAg seroconverting donors $\left(\mathrm{IDI}_{s 1}\right)$, thus leading to the following expression [64]:

$$
\text { Residual risk }=\frac{\sum s 1}{n_{\text {rd }}\left(\mathrm{WP} / \mathrm{Mdn}\left(\mathrm{IDI}_{s 1}\right)\right)} .
$$

Again, median is motivated by a small number of HBsAg seroconverting donors, and average preseroconversion interval depends on the test sensibility. The cumulative incidence estimate used here is a proportion which does not take into account a variable person-time denominator as opposed to the incidence density or rate.

3.3. HBsAg Yield. Another method for estimating HBV incidence and residual risk was named "HBsAg yield method" $[16,85,86]$. It requires both $\mathrm{HbsAg}$ and anti-HBc serologic markers. It modifies the case definition in the MüllerBreitkreutz model by considering as seroconverters only those $\mathrm{HBsAg}$-positive repeat donors who were also anti-HBc negative $(s 2)$, thus excluding those who tested positive on both markers. Then the probability of an infected repeat donor is again estimated by cumulative incidence $\left(s 2 / n_{\mathrm{rd}}\right)$ and the probability of an infected WP donation by dividing the window duration by the median IDI for HBsAg seroconverting donors $\left(\mathrm{IDI}_{s 2}\right)$, thus leading to the following expression for calculating the residual risk (RR):

$$
\text { Residual risk }=\frac{\sum s 2}{n_{\text {rd }}\left(\mathrm{WP} / \mathrm{Mdn}\left(\mathrm{IDI}_{s 2}\right)\right)} .
$$

The cumulative incidence is called the "yield rate" [65], although it is not a density-type incidence estimator to which the expression "rate" is normally applied in epidemiology. The HBsAg preseroconversion interval is restricted by the onset time for anti-HBc and is named "yield window". The ratio of the cumulative incidence between the repeat and the first-time donors is denominated the "yield rate ratio" 
TABLE 1: Principal methods for the calculation of HBV residual risk based on serological markers HBsAg and/or anti-HBc.

\begin{tabular}{|c|c|c|c|c|}
\hline Method (reference) & $\begin{array}{l}\text { Probability of HBV } \\
\text { infection }\end{array}$ & Incidence type & $\begin{array}{l}\text { Probability of window-period } \\
\text { donation }\end{array}$ & WP (days) \\
\hline Standalone HBsAg [63] & $\sum s 1 / \sum$ pyrs & Rate & $0.7\left(\sum s 1 / \mathrm{Mdn}\left(\mathrm{IDI}_{s 1}\right)\right)+0.05$ & 59 \\
\hline Müller-Breitkreutz model [64] & $\sum s 1 / n_{\mathrm{rd}}$ & Cumulative & $\mathrm{WP} / \mathrm{Mdn}\left(\mathrm{IDI}_{s 1}\right)$ & 59 \\
\hline HBsAg yield [65] & $\sum s 2 / n_{\mathrm{rd}}$ & Cumulative & $\mathrm{WP} / \mathrm{Mdn}\left(\mathrm{IDI}_{s 2}\right)$ & 44 \\
\hline HBsAg and anti-HBc yield [66] & $\sum s 3 / \sum$ pyrs & Rate & $\begin{array}{c}1 \text { if anti-HBc positive, } \\
0.7\left(\sum s 1 / \sum \mathrm{IDI}_{s 1}\right)+0.05 \text { if } \\
\text { HBsAg+ and anti-HBc negative; } \\
\approx 1\end{array}$ & 44 \\
\hline Modified standalone HBsAg [44] & $\sum s 1 / \sum$ pyrs & Rate & $\mathrm{WP} /$ Mean $\left(\mathrm{IDI}_{s 1}\right)$ & 59 \\
\hline
\end{tabular}

$s 1$ : number of HBsAg-seroconverting repeat donors (independent of anti-HBc result).

$s 2$ : number of HBsAg-seroconverting repeat donors who were anti- $\mathrm{HBc}$ negative on all testing occasions.

s3: number of HBsAg- or anti-HBc-seroconverting repeat donors (in the last 365 days).

$n_{\mathrm{rd}}$ : number of repeat donors.

WP: duration of immunologic window period.

IDI: interdonation interval (between last seronegative and first seropositive donation).

Pyrs: person-years at risk for $\mathrm{HBV}$ infection ( $\sum \mathrm{IDI}$ for all repeat donors $-0.5 \sum \mathrm{IDI}_{s 1}$ ).

Mdn: median.

and is used as a risk ratio estimate for HBV seroconversion, that is, as a multiplying factor which allows to extrapolate the residual risk calculation to the first-time donors as well. This is an important gain over the methods restricted to repeat donors only whose residual risks are known to be significantly lower when compared to the first-time donors from the past research. However, it is worth noticing that the use of cumulative incidence ratio between the groups under comparison may be applied to any method willing to assume the accuracy of this approximation.

3.4. Extended Yield Method (HBsAg and Anti-HBc Yield). Recently, an extension of the yield method was proposed to include anti-HBc (IgM and $\operatorname{IgG}$ ) seroconverting donors within last year in addition to the HBsAg only seroconverters [66]. In other words, the repeat donor who had tested anti$\mathrm{HBC}$ negative on previous donation not longer than a year ago and tested anti- $\mathrm{HBc}$ positive after that is considered an incident HBV case, despite negative HBsAg test results on both occasions. By analogy, such cases may be considered "anti$\mathrm{HBc}$ yield". These donors are most likely recently infected due to the relatively short IDI. As recrudescent HBV infection is a very rare event for repeat donors due to previous screening history and low HBV incidence in this group, the appeal of adding anti-HBc is twofold: (a) it reduces the probability of false negative screening result due to the transient nature of HBsAg marker and propensity to primary antibody response, and (b) it increases the precision of the incidence estimates by including more cases; typically, the anti-HBc yield is greater than the HBsAg one in a blood bank setting. This simply reflects the higher probability of finding a stable and often permanent marker of HBV infection such as core antibody compared to a transient marker such as surface antigen whose average duration is only 63 days [63].

3.5. Other Methodological Considerations. There are several additional methodological issues to be considered. First, the misclassification of seroconverting cases depends on their confirmation algorithm. For a HBsAg reactive test, it may require the same result on subsequent independent blood samples or anti-HBc or HBV NAT positive results [65]. In addition, $S / O$ values exceeding six may also be used to reduce false positive fraction for $\mathrm{HBs} \mathrm{Ag}$. Some authors have proposed HBV confirmation criteria based on reactive anti$\mathrm{HBC}$ and a variety of other markers of HBV infection, such as anti-HBc IgM, anti-HBe, anti-HBs without receiving the HBV vaccine, or HBV DNA [81]. However, many blood banks in the developing countries use, routinely only, only anti-HBc total (IgM + IgG) and HBsAg with subsequent testing for anti-HBs if any of the former were reactive. It is worth noticing that self-reported HBV immunization may be inaccurate, particularly regarding the number of doses received. In order to overcome these limitations, a simplified criterion of repeatedly reactive $\mathrm{HBs} \mathrm{Ag}$ or anti-HBc has been proposed for the confirmation of an incident $\mathrm{HBV}$ infection [66].

For the first-time donors, a variety of methods to calculate the HBV seroconversion risk ratio of these to repeat donors were reviewed by Soldan et al. [44]. First, the ratio of the HBsAg seroconverting fractions can be calculated between the two donor subpopulations. Second, the anti$\mathrm{HBc}$ prevalence may be used as an estimate of cumulative $\mathrm{HBV}$ incidence because this marker is persistent in the vast majority of HBV-infected individuals since the sixth month after the infection. Third, the time at risk for the first-time donors may be estimated by assuming that they were exposed to HBV since birth and that the infection occurred at the mid-point of exposure time, so that it equals half their age at the time of HBV-seropositive test result. Fourth, it is possible to estimate probability of the HBV infection for the firsttime donors during lifetime and their probability of donating blood during infectious window period, so that multiplying these probabilities (assuming that they are independent) gives an estimate of a window-period donation for this group. The next step is to multiply this estimate by the HBVseropositive fraction among the first-time donors. The same 
procedure can be applied to the repeat donors, so that the risk ratio between two donor subpopulations estimates the ratio of the window-period donation probabilities, that is, the HBV residual risk ratio.

Most of the above estimation methods have been developed for the HIV whose pandemic circulation could be estimated with reasonable precision for the purpose of these calculations. However, no such analogy exists for the HBV, thus assuming that the time of risk for HBV starting at birth is heavily dependent on the HBV vertical transmission rate which varies hugely between the countries and regions. For example, in the countries with low $\mathrm{HBV}$ prevalence and universal child vaccination, the risk of $\mathrm{HBV}$ infection in childhood is extremely low as compared to hyperendemic areas with high vertical transmission rate. Given all these uncertainties regarding the first-time donors time at risk for HBV infection, a simulation of various parameters seems a sensible approach [44].

\section{Simulation Study}

This section describes a simulation study to test the performance of the five incidence/window models based on routine serologic screening (Table 1). A description of the simulated data parameters and statistical methods is presented first, followed by the results of the data analysis, their interpretation, and brief discussion of the main findings.

4.1. Data. Two artificial datasets were created in order to test the accuracy of the selected incidence/window-period models based on serological markers $\mathrm{HBsAg}$ and anti-HBc (Table 1): one with high HBV prevalence of $4.36 \%$, defined by reactivity to either or both of the markers, and another with approximately tenfold-lower prevalence of $0.48 \%$. The choice of these values is somewhat arbitrary but still represents well the typical range of high-to-low HBV prevalence worldwide. A relatively small-size sample for this type of study was set to 100.000 donors for each prevalence level, with 23693 and 24646 person-years of followup between last seronegative and subsequent seropositive donation for the repeat donors (Table 2). The followup time is also known as interdonation interval (IDI), simulated by a beta distribution with long tails to the right to allow for a small fraction of donors with long IDI. Equal chance of HBV infection was assumed over the IDI by setting the date of infection within IDI at random for each donor. The time at risk for HBV infection was the difference between the randomly chosen date of infection and the date of previous seronegative donation for each infected donor. Mean IDI was set at about 100 days to reflect the magnitude of this parameter in various studies with observed data.

Since residual risk in the first-time donors has been found at a considerably higher level compared to the repeat donors in the vast majority of the studies, the former were set to approximately 16 times higher HBV (either marker) and about 4 times higher HBsAg prevalence than the latter (Table 2). A majority of HBV infection were HBsAg negative and anti-HBc positive to reflect the prevalence of this serologic profile in most blood bank settings, due to the much longer duration of the latter and therefore much higher probability of producing a positive serological test result.

Total and person-years of interdonation interval (IDI) were 23693 for high and 24646 for low HBV prevalence, respectively. The largest parts of these totals were contributed by seronegative repeat donors (23587 and 24634 personyears), whereas rare $\mathrm{HBsAg}$-positive and anti-HBc-negative donors contributed with 5.6 and 0.6 years for high versus low prevalence scenario. With anti-HBc-positive seroconversions in the last year counted in as incident HBV cases in the extended yield model, these figures increased to 94 and 11 person-years, in the same order. The median IDI were 100 and 110 days for the HBsAg seroconverting donors in low and high HBV prevalence groups, respectively.

As all $\mathrm{HBV}$ cases and their time at risk were true by definition, so was the HBV incidence calculated from these data, otherwise uncertain with real-life data. The discrepancy between the true and model-based incidence produced bias estimates for each incidence/window-period model (Table 3). Exact 95\% confidence intervals (CI) were also calculated assuming Poisson distribution for the number of seroconverting $\mathrm{HBV}$ cases.

For the first-time donors, no assumption was made about their HBV infection date in this paper, so no true time with HBV was known and therefore no time at risk or incidence rate could be calculated. It is possible to speculate that the first-time donors may have the same distribution of time at risk as the repeat donors and extrapolate the average (mean or median) of the latter to the former. However, this assumption may be unrealistic for many blood bank settings. Therefore, only the ratio of HBsAg-seroconverting fractions and the socalled yield rate ratio [65] were employed to estimate the residual risk in the first-time donors. The difference between the two is that the former counts in HBsAg seroconversions independently of the anti-HBc test result, whereas the latter includes only $\mathrm{HBsAg}$-positive and anti-HBc-negative cases. As $\mathrm{HBV}$ seroconversion is very rarely detected by the presence of positive test results on both markers, the two methods typically produce similar results.

For the first-time-to-repeat-donor risk ratio, the variation of the HBV residual risk estimate was calculated by substituting the central estimate by the extremes of the plausible HBV seroconversion window period (30-38 days) as in the source paper [65]. On the other hand, 95\% CI of the HBV seroconversion risk ratio was used to multiply the $\mathrm{HBV}$ residual risk estimate of the repeat donors and to arrive at 95\% CI for the first-time donors, based on the extended yield method.

Data simulation and all calculations were performed by Stata software [87].

4.2. Results. Main results of simulated residual risk for HBV according to the estimation methods and prevalence level are presented (Table 3 ).

For the high HBV prevalence (4.36\%) data, both standalone [63] and its modified version based on cumulative incidence [44] underestimated the true residual risk by $50 \%$ and $56 \%$, respectively (Table 3 ), whereas the HBsAg yield model [65] resulted in a more than tenfold underestimate. On 
TABLE 2: Simulated data: serologic profile and followup for high versus low HBV prevalence datasets.

\begin{tabular}{|c|c|c|c|c|c|}
\hline & \multicolumn{2}{|c|}{ First-time } & \multicolumn{3}{|c|}{ Repeat } \\
\hline & $n$ & Prevalence (\%) & $n$ & Prevalence (\%) & Total years at risk \\
\hline \multicolumn{6}{|c|}{$\begin{array}{l}\text { High HBV prevalence: serologic } \\
\text { profile }\end{array}$} \\
\hline HBsAg-, anti-HBc- & 47820 & $\mathrm{NA}$ & 47820 & NA & 23586.63 \\
\hline HBsAg-, anti-HBc+ & 4000 & 7.70 & 200 & 0.42 & 50.43 \\
\hline $\mathrm{HBsAg}+$, anti-HBc- & 100 & 0.19 & 20 & 0.04 & 3.29 \\
\hline HBsAg+, anti-HBc+ & 30 & 0.06 & 10 & 0.02 & 1.38 \\
\hline All & 51950 & 7.95 & 48050 & 0.48 & 23641.73 \\
\hline \multicolumn{6}{|c|}{$\begin{array}{l}\text { Low HBV prevalence: serologic } \\
\text { profile }\end{array}$} \\
\hline HBsAg-, anti-HBc- & 49587 & NA & 49977 & NA & 24634.49 \\
\hline HBsAg-, anti-HBc+ & 400 & 0.800 & 20 & 0.040 & 4.38 \\
\hline HBsAg+, anti-HBc- & 10 & 0.020 & 2 & 0.004 & 0.47 \\
\hline HBsAg+, anti-HBc+ & 3 & 0.006 & 1 & 0.001 & 0.14 \\
\hline All & 50000 & 0.826 & 50000 & 0.046 & 24639.48 \\
\hline
\end{tabular}

n: number of cases, “+”: positive test result, and “-”: negative test result.

the other hand, the Müller-Breitkreutz model overestimated the risk by more than $80 \%$. None of these models covered the true residual risk within its 95\% CI. However, the HBsAg and anti-HBc yield model [66] produced only a slight underestimate of less than $5 \%$ and covered the true value of residual risk within their $95 \%$ confidence intervals.

For the low prevalence $(0.48 \%)$ scenario, the standalone HBsAg model [63], its modification by Soldan et al. [44], and the Müller -Breitkreutz model all overestimated the true RR, whereas the HBsAg yield model underestimated it (Table 3). The yield and Müller -Breitkreutz models did not include the true residual risk value within their $95 \%$ confidence intervals, but the other models analyzed did. Again, the extended yield model including both HBsAg- and anti-HBc-seroconverting donors within last year [66] was the closest to the true residual risk with a slight underestimate of less than $6 \%$.

For the first-time donors, the ratio of HBsAg-seroconverting fractions and the socalled yield rate ratio [65] were employed to estimate the residual risk in the first-time donors (Table 4). Although in principle it would be possible to calculate the first-time donor residual risk estimates for all of the methods analyzed here (Table 3), only two of them were selected for this exercise because their proponents defined the formulas for the extrapolation from the repeat to the first donor. The other methods have not specified in exact terms how to deal with various sources of variation relevant for this calculation.

The incidence ratio estimates for the first-time to repeat donors were similar for both methods, but corresponding residual risk estimates remained much further apart (Table 4). In the simulated data, the HBV prevalence ratio between the first-time and repeat donors was set to 16.56 (7.95\% versus $0.48 \%)$ for the high prevalence and 17.96 $(0.826 \%$ versus $0.046 \%)$ for the low prevalence scenario (Table 2). Residual risk ratio between two donor subpopulations should follow the true prevalence ratio, assuming that other risk factors for HBV infection are equally distributed between them. A comparison of the true and estimated residual risk ratios is presented in Table 5.

Both methods grossly underestimated the "true" estimate, thus illustrating the difficulties in extrapolating the residual risk from repeat to first-time donors solely on the basis of their $\mathrm{HBV}$ prevalence ratio. Better estimates remain a challenge for the researchers in this area.

\section{Discussion}

The utility of anti-HBc marker in HBV screening of blood donors has been pointed out in various publications [33, 8890]. It was argued that HBV MP NAT would not detect most anti-HBc-positive donors with low viral load, whereas more sensitive assays such as PRISM HBCore would provide a yield of $1: 49.000$ [88]. Although HBsAg assays are more sensitive in detecting $\mathrm{HBV}$ window-period infections, anti-HBc test can detect chronic carriers with low-level viremia without detectable HBsAg. The first few years of adding HBV NAT to routine screening of blood donations in the USA and Germany showed only a small yield $[12,36]$, and other studies pointed out that $3 \%$ of $\mathrm{HBV}$-infected donations would remain undetected even by ID NAT, thus reinforcing the need to maintain the HBsAg marker for routine blood screening [91]. More recently, PRISM CLIA claimed a $60 \%$ reduction of the HBV residual risk over MP NAT, from $1: 385.555$ to $1: 610.488$ [92]. These findings provide strong arguments that improved sensitivity of serologic screening for $\mathrm{HBV}$ is a viable option for some blood bank settings.

Although by the first half of the 2000 decade NAT screening for HIV and HCV showed poor yield in many countries which had implemented it for routine blood screening $[12,41-44,46,55,56]$, the extension of this method to HBV topped the agenda of new strategies for blood donor screening [90]. The observed NAT yield was reasonably close 
TABLE 3: HBV incidence adjusted for the probability of detecting transient HBsAg marker (PWP) and residual risk (RR) for repeat donors.

\begin{tabular}{|c|c|c|c|c|}
\hline HBV prevalence & Method (reference) & $\begin{array}{c}\text { Probability of HBV } \\
\text { infected }^{1}\end{array}$ & PWP & RR (95\% CI) \\
\hline \multirow{6}{*}{ High } & True values & 0.0097286 & 1.0000 & $1: 636$ \\
\hline & Standalone HBsAg [63] & $\begin{array}{c}0.0012664 \\
(0.003286,0.001808)\end{array}$ & 0.2600 & $\begin{array}{c}1: 1270 \\
(1: 890,1: 1883)\end{array}$ \\
\hline & Müller-Breitkreutz [64] & $\begin{array}{c}0.0047867 \\
(0.00419,0.005447)\end{array}$ & 0.5906 & $\begin{array}{c}1: 354 \\
(1: 311,1: 404)\end{array}$ \\
\hline & Modified standalone HBsAg [44] & $\begin{array}{c}0.0012664 \\
(0.00085,0.00181)\end{array}$ & 0.5506 & $\begin{array}{c}1: 1434 \\
(1: 1005,1: 2126)\end{array}$ \\
\hline & HBsAg yield ${ }^{2}[65]$ & 0.000416 & $0.2991,0.3789$ & $\begin{array}{c}1: 7092 \\
(1: 6345,1: 8037)\end{array}$ \\
\hline & HBsAg and anti-HBc yield [66] & $\begin{array}{c}0.0092818 \\
(0.0081,0.0106) \\
\end{array}$ & 0.99 & $\begin{array}{c}1: 667 \\
(1: 95,1: 765)\end{array}$ \\
\hline \multirow{6}{*}{ Low } & True values & 0.0009438 & 1.0000 & $1: 6555$ \\
\hline & Standalone HBsAg [63] & $\begin{array}{c}0.0001217 \\
(0.0000251,0.000357)\end{array}$ & 0.19856 & $\begin{array}{c}1: 1632 \\
(1: 556,1: 7911)\end{array}$ \\
\hline & Müller-Breitkreutz [64] & $\begin{array}{c}0.000600 \\
(0.0000124,0.0001753)\end{array}$ & 0.5444 & $\begin{array}{c}1: 30615 \\
(1: 10479,1: 148136)\end{array}$ \\
\hline & Modified standalone HBsAg [44] & $\begin{array}{c}0.0001217 \\
(0.0000251,0.000357)\end{array}$ & 0.5444 & $\begin{array}{c}1: 15093 \\
(1: 5145,1: 73183)\end{array}$ \\
\hline & HBsAg yield ${ }^{2}[65]$ & $\begin{array}{c}0.000400 \\
(0.0000048,0.0001445)\end{array}$ & $0.2731,0.3460$ & $\begin{array}{c}1: 8052 \\
(1: 7225,1: 9152)\end{array}$ \\
\hline & HBsAg and anti-HBc yield [66] & $\begin{array}{c}0.000893 \\
(0.00056,0.00135)\end{array}$ & 0.99 & $\begin{array}{c}1: 6929 \\
(1: 4577,1: 11057)\end{array}$ \\
\hline
\end{tabular}

${ }^{1}$ Probability of HBV-infected donation (HBV incidence).

${ }^{2}$ Instead of $95 \% \mathrm{CI}$, a range between the extremes of the window period (30-38 days) is given.

TABLE 4: HBV residual risk (RR) estimates for the first-time donors.

\begin{tabular}{|c|c|c|c|c|c|c|c|c|c|}
\hline \multirow{2}{*}{ Method } & \multirow{2}{*}{ HBV prevalence } & \multicolumn{3}{|c|}{ First-time donors } & \multicolumn{3}{|c|}{ Repeat donors } & \multirow{2}{*}{ IR (variation) ${ }^{\mathrm{c}}$} & \multirow{2}{*}{$\begin{array}{l}\text { RR for the first-time donors } \\
\text { (variation) })^{\mathrm{d}}\end{array}$} \\
\hline & & $s^{\mathrm{a}}$ & $n$ & $(\%)^{\mathrm{b}}$ & $s^{\mathrm{a}}$ & $n$ & $(\%)^{\mathrm{b}}$ & & \\
\hline \multirow[t]{2}{*}{ HBsAg yield } & High & 100 & 51950 & 0.1925 & 20 & 48050 & 0.0416 & 4.62 & $\begin{array}{c}1: 1533 \\
(1: 888,1: 2843)\end{array}$ \\
\hline & Low & 10 & 50000 & 0.0200 & 2 & 50000 & 0.0040 & 5.00 & $\begin{array}{c}1: 1610 \\
(1: 4000,1: 151280) \\
\end{array}$ \\
\hline \multirow{2}{*}{$\begin{array}{l}\text { HBsAg and } \\
\text { anti-HBc yield }\end{array}$} & High & 130 & 51950 & 0.2500 & 30 & 48050 & 0.0624 & $4.01(2.69,5.96)$ & $\begin{array}{c}1: 166 \\
(1: 112,1: 247)\end{array}$ \\
\hline & Low & 13 & 50000 & 0.0260 & 3 & 50000 & 0.0060 & $4.33(1.23,15.20)$ & $\begin{array}{c}1: 1599 \\
(1: 456,1: 5610)\end{array}$ \\
\hline
\end{tabular}

${ }^{\mathrm{a}}$ Number of HBV-seroconverting donors.

${ }^{b}$ Percentage of HBV-seroconverting donors.

${ }^{\mathrm{c}} \mathrm{IC}$ : Incidence ratio for the first-time to repeat donor; no variation was calculated for the yield method whereas $95 \% \mathrm{CI}$ of the risk ratio was used for the HBsAg and anti-HBc yield method.

${ }^{\mathrm{d}}$ Multiplies of the plausible range for the yield method versus 95\% CI of the risk ratio for the HBsAg and anti-HBc yield method.

to the values predicted by incidence/window model. A 24sample minipool NAT for HBV showed a yield of $1: 352.451$ over routine serologic screening, thus of a similar magnitude as HIV and HCV yield observed [93]. The downside of HBV NAT was small yield and cost-effectiveness in low prevalence areas, especially with minipool NAT, as well as the lack of sensitivity of even ID NAT to detect extremely sparse HBV DNA particles involved in transmission by transfusion. Under most circumstances, serologic screening with HBsAg and anti-HBc should be maintained, thus adding to the cost of HBV NAT. As epidemiologic parameters and financial aspects vary immensely across countries worldwide, the cost-effectiveness of HBV NAT should be a country-specific decision $[90,94]$.

A range of methodological improvements for estimating the $\mathrm{HBV}$ residual risk deserves to be mentioned. The shift to probabilistic modeling of residual risk parameters [95] based on HBV viral load allowed a distinction between early versus late window-period seroconversions. Sensitive tests of the viral load such as HBV ID NAT and serologic profile ( $\mathrm{HBsAG}$, anti-HBc, and anti-HBs; rarely anti-HBe) provide clues to identify $\mathrm{OBI}$ and/or chronic carriers with low viremia $[7,96]$. New animal models for HBV transmission have been developed, such as inoculating chimeric mice 
TABLE 5: Comparison of HBV residual risk (RR) estimates for the first-time and repeat donors.

\begin{tabular}{lcccc}
\hline $\begin{array}{l}\text { Residual risk } \\
\text { estimation method }\end{array}$ & \multicolumn{2}{c}{ HBsAg yield } & \multicolumn{2}{c}{$\begin{array}{c}\text { HBsAg and } \\
\text { anti-HBc yield }\end{array}$} \\
\hline HBV prevalence & High & Low & High & Low \\
Repeat donor RR & $1: 7092$ & $1: 8052$ & $1: 667$ & $1: 6929$ \\
First-time donor RR & $1: 1533$ & $1: 1610$ & $1: 1599$ & $1: 1610$ \\
Estimated RRR $^{\mathrm{a}}$ & 12.82 & 5.00 & 4.08 & 4.33 \\
True RRR $^{\mathrm{b}}$ & 16.56 & 17.96 & 16.56 & 17.96 \\
\hline
\end{tabular}

${ }^{a}$ Residual risk ratio of first-time to repeat donors.

${ }^{\mathrm{b}}$ Best estimate based on HBV prevalence ratio of first-time to repeat donor.

with human hepatocytes by human HBV [97]. In addition, a recent study claimed great diagnostic accuracy of the differential expression of HBV microRNA profile in serum for identifying OBI [98].

However, for the vast majority of HBV infections located in the developing countries, routine serologic screening with $\mathrm{HBsAg}$ and anti-HBc remains the best affordable strategy for the time being and probably for at least a decade ahead. As the countries that have initiated universal child vaccination against HBV did so a decade or two ago, the influx of the vaccinated blood donors has only started to reduce the HBV residual risk very slowly due to the vast majority of unvaccinated donors. Targeting blood donors with HBV vaccine has been recommended to increase the blood safety in such situation $[74,99]$, and a study showed that its costeffectiveness may be as high as introducing HBV ID NAT in a low-prevalence country such as Germany (Ringwald 2005) [35]. In moderate-to-high prevalence countries, the costeffectiveness is bound to lean even more towards enhancing the targeted vaccination strategy.

Whatever the national strategy to increase the blood safety is, it is essential to base it on sound epidemiological data and systematic monitoring of the residual risk. To that end, extended yield model including both HBsAg and recent anti-HBc seroconversions in repeat donors provides a simple, accurate, and affordable method. It is suitable for smaller blood bank settings of the order of hundred thousand donors as opposed to huge samples of the order of several million donors employed by the other methods; all of which were developed in the developed countries with low HBV prevalence. The extended yield method was shown to both reduce the bias and improve the HBV residual risk precision, so it may be sensitive enough for monitoring the residual risk time trend in a particular setting.

Although the criterion for the definition of HBV prevalence as high, intermediate, or low in the general population (WHO) are often extended to the blood donor population, it should be avoided for two reasons. First, the latter population should have a considerably lower risk for a variety of bloodborne diseases, with $\mathrm{HBV}$ at the top of this list, as it is predominantly sexually transmitted and therefore a marker of risky sexual behavior. Second, HBV infection is preventable by immunization affordable to virtually every country, so the criterion of what is high or low prevalence should be set against the real opportunity to reduce its prevalence to the order of few cases per 100.000 in the adult population and perhaps even per million in the blood donor population. Some developed countries like Great Britain have achieved this level of HBV risk reduction [46], while many other are on their way. However, immigration from higher-prevalence countries has been observed as an important factor in reducing the $\mathrm{HBV} \mathrm{RR}$, particularly among the first-time donors (O’Brien et al. 2008; Brant et al. 2011) [21, 46]. Global health policy for reducing HBV prevalence should therefore give a special place to offering a cost-free $\mathrm{HBV}$ immunization to these donors in the country of immigration if it was not successive in the country of origin.

\section{Residual Risk Estimation: Limitations and Perspectives}

There are several limitations of this work which should be borne in mind. First, it is beyond its scope to address the question of $\mathrm{HBV}$ infectivity regarding either the phase of HBV infection or the host factors. Residual risk is limited to the probability of an infected blood unit being erroneously considered noninfectious and thus transfusable, so it fell short of taking into account other factors related to posttransfusion HBV infection, let alone its severity and clinical evolution.

Second, many incidence/window-period model parameters are pretty variable both between regions and between blood donors but their variation is typically underestimated in the calculation. For example, the repeat donors vary considerably regarding their IDI and consequently the time at risk of $\mathrm{HBV}$ infection. However, only average IDI is normally used for calculations, so this work followed the same tradition. IDI distribution is often heavy tailed to the right because of a small number of large values, thus adding the choice of the distribution to the uncertainties of the model. Again, this issue was ignored here to make the results comparable to those published in the literature.

Third, as the host response to HBV infection is highly variable, so is the time for HBsAg to reach the threshold of detectability for a given sensibility of a screening test, as well as the duration of the of socalled eclipse phase [100] before HBV starts circulating in peripheral blood. In addition to the onset, the duration of HBsAg detectability is also variable between individuals and correlated with the onset of producing neutralizing antibodies. The eclipse period is by definition noninfectious and therefore should be excluded from the incidence/window-period model calculation, resulting in its reduction for approximately a week [100].

Fourth, the extrapolation of the HBV residual risk from the repeat to the first-time donors is based on a number of simplifying assumptions mentioned earlier, whose impact on the estimate variation has not been quantified except in a very simple way by applying the $95 \% \mathrm{CI}$ of the relative risk of $\mathrm{HBV}$ seroconversion in the extended yield model. The inference about incidence rate of a viral disease based on its prevalence is prone to considerable amount of error [101] and so is any extrapolation from the repeat to the first-time donors using these premises. 
All of these limitations result in a considerable underestimation of the residual risk variation by traditional methods of calculation. This may seem paradoxal as many published results already present wide confidence intervals even in the samples of the order of hundred thousands due to the very low frequency of seroconversion among repeat donors. However, virtually all of them account only for the random variation in the number of seroconversions and leave out other sources of variation discussed above. Simulation of a joint impact of various sources of variation was used a decade ago [44] but remained an exception instead of becoming a rule. With the advance of stochastic simulation software, Bayesian analysis has much to offer to this research area.

The underestimation of the HBV residual risk variation may have different impact for low versus high prevalence area. Most of the research has been done in the developed countries with low HBV prevalence, where the number of HBV seroconversions among repeat donors is very rare. On the other hand, with mean being equal to the variance in Poisson distribution used to model the variation in the number of seroconversions, high HBV prevalence makes larger means of seroconverting donors per unit time more likely, as well as their variance.

Although artificial data are the only way to guarantee certainty of a residual risk model parameters, eventually the utility of any model has to be tested with real data. It is important to monitor the $\mathrm{HBV}$ residual risk on a regular basis and look for its regional and sociodemographic variations in order to better understand the blood donor behavior and to direct preventive actions accordingly. Routine gathering of relevant epidemiologic data is necessary for both the blood donor and the general population to provide a solid basis for the incidence/window-period models. The knowledge of hepatitis B viral dynamics gathered with evermore sensitive NAT can be used to further improve the incidence/windowperiod model calculations and validate its robustness and precision.

Despite its limitations compared to the HBV DNA testing, the incidence/window-period model continues to play an important role in blood screening. It is the only affordable method for many developing countries which contain vast majority of the people with HBV in the world. Even for the countries with resources for the HBV DNA blood screening, serologic testing with $\mathrm{HBsAg}$ and anti-HBc still prevents some posttransfusion hepatitis $\mathrm{B}$ caused by $\mathrm{OBI}$ and chronic HBV carriers, although deferral of the donors with transfusable blood may be high. More sensitive serologic tests and targeting HBV vaccination of blood donors could be costeffective alternatives in some cases [35]. The latter may also be a half-way to extend the vaccination to potential donors as well. Although it is not a typical task for a blood bank, it may be part of its strategy to recruit new donors and rise awareness of the importance of HBV prevention. In the countries where access to health services is limited, offering the vaccine within a blood bank may be an important logistic facilitator of such policy.

In conclusion, the incidence/window-period model for HBV has been around for 15 years and remains relevant for evaluating the HBV residual risk in vast majority of the developing countries which concentrate the bulk of the people with HBV worldwide. The model has been improved over the years, benefiting from the insights on viral dynamics based on the research with highly sensitive HBV NAT. An adaptation of the incidence/window-period model termed "extended yield model", which considers both HBsAg and recently (within last year) seroconverting anti-HBc repeat donors, seems particularly suitable for evaluating the HBV residual risk in smaller blood bank settings due to its robustness against bias and increased precision. Systematic monitoring of this risk and corresponding incidence are indispensable for improving the blood safety regarding HBV, still being the most common posttransfusional infection.

\section{Abbreviations}

Anti-HBc: Hepatitis B core antibody

Anti-HBe: Hepatitis B e antibody

Anti-HBs: Antibody to hepatitis B surface antigen

HBsAg: Hepatitis B surface antigen

HBV: Hepatitis B virus

HCV: Hepatitis $\mathrm{C}$ virus

ID NAT: Individual donation nucleic acid testing

MP NAT: Minipool nucleic acid testing

NAT: $\quad$ Nucleic acid testing

OBI: Occult hepatitis B infection.

\section{Acknowledgment}

This work was partially supported by the Brazilian Ministry of Science (CNPQ) Grant no. PQ 300578/2007-5.

\section{References}

[1] WHO, “Hepatitis B," 2002, http://www.who/cds/csr/lyo/2002.2: HepatitisB.

[2] WHO, "Disease burden from viral hepatitis A, B, and C in the United States," 2013, http://www.cdc.gov/hepatitis/HBV/ StatisticsHBV.htm\#section 4 .

[3] S. T. Goldstein, F. Zhou, S. C. Hadler, B. P. Bell, E. E. Mast, and H. S. Margolis, "A mathematical model to estimate global hepatitis B disease burden and vaccination impact," International Journal of Epidemiology, vol. 34, no. 6, pp. 1329-1339, 2005.

[4] A. Donabedian, "Evaluating the quality of medical care," The Milbank Memorial Fund Quarterly, vol. 44, no. 3, pp. 166-206, 1966.

[5] A. Pereira, "Health and economic impact of posttransfusion hepatitis B and cost-effectiveness analysis of expanded HBV testing protocols of blood donors: a study focused on the European Union," Transfusion, vol. 43, no. 2, pp. 192-201, 2003.

[6] R. Reddy, M. Vermeulen, N. Lelie et al., "Impact of individualdonation nucleic acid testing on risk of human immunodeficiency virus, hepatitis B virus, and hepatitis $\mathrm{C}$ virus transmission by blood transfusion in South Africa," Transfusion, vol. 49, no. 6, pp. 1115-1125, 2009.

[7] M. Vermeulen, C. Dickens, N. Lelie et al., "Hepatitis B virus transmission by blood transfusion during 4 years of individualdonation nucleic acid testing in South Africa: estimated and observed window period risk," Transfusion, vol. 52, no. 4, pp. 880-892, 2012. 
[8] B. A. Borkent-Raven, M. P. Janssen, C. L. van der Poel, G. A. de Wit, G. J. Bonsel, and B. A. van Hout, "Cost-effectiveness of additional hepatitis B virus nucleic acid testing of individual donations or minipools of six donations in the Netherlands," Transfusion, vol. 49, no. 2, pp. 311-319, 2009.

[9] S. Kleinman, M. R. King, M. P. Busch, E. L. Murphy, S. A. Glynn, and The National Heart Lung Blood Institute Retrovirus Epidemiology Donor Study and Retrovirus Epidemiology Donor Study-II, “The National Heart, Lung, and Blood Institute retrovirus epidemiology donor studies (Retrovirus Epidemiology Donor Study and Retrovirus Epidemiology Donor StudyII): twenty years of research to advance blood product safety and availability," Transfusion Medicine Review, vol. 26, no. 4, pp. 281-304, 2012.

[10] R. Y. Dodd, S. L. Orton, E. P. Notari IV, and S. L. Stramer, "Viral marker rates among blood donors before and after the terrorist attacks on the United States on September 11, 2001," Transfusion, vol. 42, no. 9, pp. 1240-1241, 2002.

[11] S. A. Glynn, M. P. Busch, G. B. Schreiber et al., "Effect of a national disaster on blood supply and safety: the September 11 experience," Journal of the American Medical Association, vol. 289, no. 17, pp. 2246-2253, 2003.

[12] B. R. Jackson, M. P. Busch, S. L. Stramer, and J. P. AuBuchon, "The cost-effectiveness of NAT for HIV, HCV, and HBV in whole-blood donations," Transfusion, vol. 43, no. 6, pp. 721-729, 2003.

[13] G. J. Pomper, Y. Y. Wu, and E. L. Snyder, "Risks of transfusiontransmitted infections: 2003," Current Opinion in Hematology, vol. 10, no. 6, pp. 412-418, 2003.

[14] J. P. Allain, P. E. Hewitt, R. S. Tedder, and L. M. Williamson, "Evidence that anti-HBc but not HBV DNA testing may prevent some HBV transmission by transfusion," British Journal of Haematology, vol. 107, no. 1, pp. 186-195, 1999.

[15] R. Y. Dodd, "Current safety of the blood supply in the United States," International Journal of Hematology, vol. 80, no. 4, pp. 301-305, 2004.

[16] S. Zou, S. L. Stramer, E. P. Notari et al., "Current incidence and residual risk of hepatitis B infection among blood donors in the United States,” Transfusion, vol. 49, no. 8, pp. 1609-1620, 2009.

[17] S. Zou, S. L. Stramer, and R. Y. Dodd, "Donor testing and risk: current prevalence, incidence, and residual risk of transfusiontransmissible agents in US allogeneic donations," Transfusion Medical Review, vol. 26, no. 2, pp. 119-128, 2012.

[18] J. A. Chiavetta, M. Escobar, A. Newman et al., "Incidence and estimated rates of residual risk for HIV, hepatitis C, hepatitis $\mathrm{B}$ and human T-cell lymphotropic viruses in blood donors in Canada, 1990-2000," CMAJ, vol. 169, no. 8, pp. 767-773, 2003.

[19] S. F. O’Brien, Q. L. Yi, W. Fan, V. Scalia, S. H. Kleinman, and E. C. Vamvakas, "Current incidence and estimated residual risk of transfusion-transmitted infections in donations made to Canadian Blood Services," Transfusion, vol. 47, no. 2, pp. 316$325,2007$.

[20] S. F. O’Brien, M. A. Fearon, Q. L. Yi et al., “Hepatitis B virus DNA-positive, hepatitis $\mathrm{B}$ surface antigen-negative blood donations intercepted by anti-hepatitis B core antigen testing: the Canadian Blood Services experience," Transfusion, vol. 47, no. 10, pp. 1809-1815, 2007.

[21] S. F. O’Brien, G. Xi, W. Fan et al., "Epidemiology of hepatitis B in Canadian blood donors," Transfusion, vol. 48, no. 11, pp. 23232330, 2008.

[22] J. J. Weusten, H. A. van Drimmelen, and P. N. Lelie, "Mathematic modeling of the risk of $\mathrm{HBV}, \mathrm{HCV}$, and HIV transmission by window-phase donations not detected by NAT,' Transfusion, vol. 42, no. 5, pp. 537-548, 2002.

[23] M. Alvarez do Barrio, R. González Díez, J. M. Hernández Sánchez, and S. Oyonarte Gómez, "Residual risk of transfusiontransmitted viral infections in Spain, 1997-2002, and impact of nucleic acid testing," Eurosurveillance, vol. 10, no. 2, pp. 20-22, 2005.

[24] R. González, J. M. Echevarria, A. Avellón, L. Barea, and E. Castro, "Acute hepatitis B virus window-period blood donations detected by individual-donation nucleic acid testing: a report on the first two cases found and interdicted in Spain," Transfusion, vol. 46, no. 7, pp. 1138-1142, 2006.

[25] M. E. Tosti, S. Solinas, D. Prati et al., "An estimate of the current risk of transmitting blood-borne infections through blood transfusion in Italy," British Journal of Haematology, vol. 117, no. 1, pp. 215-219, 2002.

[26] M. Gonzalez, V. Règine, V. Piccinini, F. Vulcano, A. Giampaolo, and H. J. Hassan, "Residual risk of transfusion-transmitted human immunodeficiency virus, hepatitis $\mathrm{C}$ virus, and hepatitis B virus infections in Italy," Transfusion, vol. 45, no. 10, pp. 16701675, 2005.

[27] P. Manzini, M. Girotto, R. Borsotti et al., "Italian blood donors with anti-HBc and occult hepatitis B virus infection," Haematologica, vol. 92, no. 12, pp. 1664-1670, 2007.

[28] C. Velati, L. Romanò, L. Fomiatti et al., "Impact of nucleic acid testing for hepatitis B virus, hepatitis $C$ virus, and human immunodeficiency virus on the safety of blood supply in Italy: a 6-year survey," Transfusion, vol. 48, no. 10, pp. 2205-2213, 2008.

[29] P. Iudicone, M. Miceli, M. Palange et al., "Hepatitis B virus blood screening: impact of nucleic amplification technology testing implementation on identifying hepatitis B surface antigen nonreactive window period and chronic infections," Vox Sanguinis, vol. 96, no. 4, pp. 292-297, 2009.

[30] C. Niederhauser, P. Schneider, M. Fopp, A. Ruefer, and G. Lévy, "Incidence of viral markers and evaluation of the estimated risk in the Swiss blood donor population from 1996 to 2003," Euro Surveillance, vol. 10, no. 2, pp. 14-16, 2005.

[31] C. Niederhauser, B. M. Taleghani, M. Graziani, M. Stolz, C. Tinguely, and P. Schneider, "Blood donor screening: how to decrease the risk of transfusion-transmitted hepatitis B virus?" Swiss Medical Weekly, vol. 138, no. 9-10, pp. 134-141, 2008.

[32] M. Stolz, C. Tinguely, M. Graziani et al., "Efficacy of individual nucleic acid amplification testing in reducing the risk of transfusion-transmitted hepatitis B virus infection in Switzerland, a low-endemic region," Transfusion, vol. 50, no. 12, pp. 2695-2706, 2010.

[33] W. K. Roth, M. Weber, D. Petersen et al., "NAT for HBV and anti-HBc testing increase blood safety," Transfusion, vol. 42, no. 7, pp. 869-875, 2002.

[34] R. Offergeld, S. Ritter, D. Faensen, and O. Hamouda, "Infection epidemiological data among blood donors in Germany 20032004. Report of the Robert Koch Institute in accordance with Article 22 of the Transfusion Act," Bundesgesundheitsblatt Gesundheitsforschung Gesundheitsschutz, vol. 48, no. 11, pp. 1273-1287, 2005.

[35] J. Ringwald, I. Mertz, R. Zimmermann et al., "Hepatitis B virus vaccination of blood donors: what costs may be expected?" Transfusion Medicine, vol. 15, no. 2, pp. 83-92, 2005.

[36] R. Offergeld, D. Faensen, S. Ritter, and O. Hamouda, "Human immunodeficiency virus, hepatitis $\mathrm{C}$ and hepatitis $\mathrm{B}$ infections among blood donors in Germany 2000-2002: risk of virus 
transmission and the impact of nucleic acid amplification testing," Euro Surveillance, vol. 10, no. 2, pp. 8-11, 2005.

[37] M. Schmidt, C. M. Nübling, H. Scheiblauer et al., "Anti-HBc screening of blood donors: a comparison of nine anti-HBc tests," Vox Sanguinis, vol. 91, no. 3, pp. 237-243, 2006.

[38] M. K. Hourfar, C. Jork, V. Schottstedt et al., "Experience of German red cross blood donor services with nucleic acid testing: results of screening more than 30 million blood donations for human immunodeficiency virus-1, hepatitis $C$ virus, and hepatitis B virus," Transfusion, vol. 48, no. 8, pp. 1558-1566, 2008.

[39] M. K. Hourfar, L. A. Walch, G. Geusendam et al., "Sensitivity and specificity of anti-HBc screening assays: which assay is best for blood donor screening?" International Journal of Laboratory Hematology, vol. 31, no. 6, pp. 649-656, 2009.

[40] R. Offergeld, S. Ritter, L. Quabeck, and O. Hamouda, "Epidemiological data on infections among blood donors in Germany 2007," Bundesgesundheitsblatt Gesundheitsforschung Gesundheitsschutz, vol. 53, no. 11, pp. 1188-1196, 2010.

[41] P. Morel, "Ten years of nucleic acid testing: lessons and prospects," Transfusion Clinique et Biologique, vol. 18, no. 2, pp. 133-139, 2011.

[42] J. Pillonel, N. Le Marrec, A. Girault, D. David, and S. Laperche, "Epidemiological surveillance of blood donors and residual risk of blood-borne infections in France, 2001 to 2003," Transfusion Clinique et Biologique, vol. 12, no. 3, pp. 239-246, 2005.

[43] A. Servant-Delmas, C. Chuteau, C. Lefort et al., "Two cases of transfusion-transmitted hepatitis $\mathrm{B}$ virus (HBV) infection in a low-endemic country before implementation of HBV nucleic acid testing," Transfusion, vol. 53, no. 2, pp. 291-296, 2012.

[44] K. Soldan, J. A. J. Barbara, M. E. Ramsay, and A. J. Hall, "Estimation of the risk of hepatitis B virus, hepatitis $C$ virus and human immunodeficiency virus infectious donations entering the blood supply in England, 1993-2001," Vox Sanguinis, vol. 84, no. 4, pp. 274-286, 2003.

[45] K. Soldan, K. Davison, and B. Dow, "Estimates of the frequency of HBV, HCV, and HIV infectious donations entering the blood supply in the United Kingdom, 1996 to 2003," Euro Surveillance, vol. 10, no. 2, pp. 17-19, 2005.

[46] L. J. Brant, C. Reynolds, L. Byrne, and K. L. Davison, "Hepatitis $\mathrm{B}$ and residual risk of infection in English and Welsh blood donors, 1996 through 2008," Transfusion, vol. 51, no. 7, pp. 14931502, 2011.

[47] M. Satake, R. Taira, H. Yugi et al., "Infectivity of blood components with low hepatitis B virus DNA levels identified in a lookback program," Transfusion, vol. 47, no. 7, pp. 1197-1205, 2007.

[48] Y. Tani, H. Aso, H. Matsukura et al., "Significant background rates of $\mathrm{HBV}$ and $\mathrm{HCV}$ infections in patients and risks of blood transfusion from donors with low anti-HBc titres or high anti$\mathrm{HBc}$ titres with high anti-HBs titres in Japan: a prospective, individual NAT study of transfusion-transmitted HBV, HCV and HIV infections," Vox Sanguinis, vol. 102, no. 4, pp. 285-293, 2012.

[49] R. Taira, M. Satake, S. Momose et al., "Residual risk of transfusion-transmitted hepatitis B virus (HBV) infection caused by blood components derived from donors with occult HBV infection in Japan," Transfusion, 2012.

[50] J. T. Wang, C. Z. Lee, P. J. Chen, T. H. Wang, and D. S. Chen, "Transfusion-transmitted HBV infection in an endemic area: the necessity of more sensitive screening for HBV carriers," Transfusion, vol. 42, no. 12, pp. 1592-1597, 2002.
[51] C. J. Liu, D. S. Chen, and P. J. Chen, "Epidemiology of HBV infection in Asian blood donors: emphasis on occult HBV infection and the role of NAT,' Journal of Clinical Virology, vol. 36, supplement 1, pp. S33-S44, 2006.

[52] L. Li, P. J. Chen, M. H. Chen, K. F. Chak, K. S. Lin, and S. J. L. Tsai, "A pilot study for screening blood donors in Taiwan by nucleic acid amplification technology: detecting occult hepatitis $B$ virus infections and closing the serologic window period for hepatitis C virus," Transfusion, vol. 48, no. 6, pp. 1198-1206, 2008.

[53] T. H. Su, P. J. Chen, T. C. Chen et al., "The clinical significance of occult hepatitis B transfusion in Taiwan: a look-back study," Transfusion Medicine, vol. 21, no. 1, pp. 33-41, 2011.

[54] M. J. Kim, Q. Park, H. K. Min, and H. O. Kim, "Residual risk of transfusion-transmitted infection with human immunodeficiency virus, hepatitis $C$ virus, and hepatitis B virus in Korea from 2000 through 2010," BMC Infectious Disease, vol. 12, no. $160,2012$.

[55] L. Al Shaer, M. Abdulrahman, T. J. John, and A. Alhashimi, "Trends in prevalence, incidence, and residual risk of major transfusion-transmissible viral infections in United Arab Emirates blood donors: impact of individual-donation nucleic acid testing, 2004 through 2009," Transfusion, vol. 52, no. 11, pp. 2300-2309, 2012.

[56] C. R. Seed, A. Cheng, S. L. Ismay et al., "Assessing the accuracy of three viral risk models in predicting the outcome of implementing HIV and HCV NAT donor screening in Australia and the implications for future HBV NAT," Transfusion, vol. 42, no. 10, pp. 1365-1372, 2002.

[57] S. Owusu-Ofori, J. Temple, F. Sarkodie, M. Anokwa, D. Candotti, and J. P. Allain, "Predonation screening of blood donors with rapid tests: implementation and efficacy of a novel approach to blood safety in resource-poor settings," Transfusion, vol. 45, no. 2, pp. 133-140, 2005.

[58] S. Jayaraman, Z. Chalabi, P. Perel, C. Guerriero, and I. Roberts, "The risk of transfusion-transmitted infections in sub-Saharan Africa," Transfusion, vol. 50, no. 2, pp. 433-442, 2010.

[59] A. O. Touré-Fall, T. N. Dièye, A. Sall et al., "Residual risk of transmission of HIV and HBV, in Senegalese national blood bank from 2003 to 2005," Transfusion Clinique Et Biologique, vol. 16, no. 5-6, pp. 439-443, 2009.

[60] H. Ouattara, L. Siransy-Bogui, C. Fretz et al., "Residual risk of HIV, HVB and HCV transmission by blood transfusion between 2002 and 2004 at the Abidjan National Blood Transfusion Center," Transfusion Clinique et Biologique, vol. 13, no. 4, pp. 242-245, 2006.

[61] A. Loua, E. M. L. Sow, F. B. Magassouba, M. Camara, and M. A. Baldé, "Evaluation of residual infectious risk among blood donors in National Center of Blood Transfusion in Conakry," Transfusion Clinique et Biologique, vol. 11, no. 2, pp. 98-100, 2004.

[62] S. Laperche and Francophone African Group for Research in Blood Transfusion, "Multinational assessment of blood-borne virus testing and transfusion safety on the African continent," Transfusion, vol. 53, no. 4, pp. 816-826, 2013.

[63] J. J. Korelitz, M. P. Busch, S. H. Kleinman et al., "A method for estimating hepatitis B virus incidence rates in volunteer blood donors," Transfusion, vol. 37, no. 6, pp. 634-640, 1997.

[64] K. Müller-Breitkreutz, "Results of viral marker screening of unpaid blood donations and probability of window period donations in 1997," Vox Sanguinis, vol. 78, no. 3, pp. 149-157, 2000 . 
[65] S. Zou, F. Musavi, E. P. Notari, S. L. Stramer, and R. Y. Dodd, "Prevalence, incidence, and residual risk of major blood-borne infections among apheresis collections to the American Red Cross Blood Services, 2004 through 2008," Transfusion, vol. 50, no. 7, pp. 1487-1494.

[66] E. Kupek and A. Petry, "Comparison of epidemiological methods for estimation of hepatitis Bincidence and residual risk for blood donors in Southern Brazil," Journal of Tranfusion, vol. 1, pp. 1-8, 2011.

[67] W. Antar, M. H. El-Shokry, W. A. Abd El Hamid, and M. F. Helmy, "Significance of detecting anti-HBc among Egyptian male blood donors negative for HBsAg," Transfusion Medicine, vol. 20, no. 6, pp. 409-413, 2010.

[68] A. Behzad-Behbahani, A. Mafi-Nejad, S. Z. Tabei, K. B. Lankarani, A. Torab, and A. Moaddeb, "Anti-HBc \& HBVDNA detection in blood donors negative for hepatitis B virus surface antigen in reducing risk of transfusion associated HBV infection," Indian Journal of Medical Research, vol. 123, no. 1, pp. 37-42, 2006.

[69] H. Altunay, E. Kosan, I. Birinci et al., "Are isolated anti-HBc blood donors in high risk group? The detection of HBV DNA in isolated anti-HBc cases with nucleic acid amplification test (NAT) based on transcription-mediated amplification (TMA) and HBV discrimination," Transfusion and Apheresis Science, vol. 43, no. 3, pp. 265-268, 2010.

[70] M. Asim, R. Ali, L. A. Khan, S. A. Husain, R. Singla, and P. Kar, "Significance of anti-HBc screening of blood donors \& its association with occult hepatitis B virus infection: implications for blood transfusion," Indian Journal of Medical Research, vol. 132, no. 9, pp. 312-317, 2010.

[71] G. Shang, C. R. Seed, F. Wang, D. Nie, and A. Farrugia, "Residual risk of transfusion-transmitted viral infections in Shenzhen, China, 2001 through 2004," Transfusion, vol. 47, no. 3, pp. 529539, 2007.

[72] F. R. Ren, J. X. Wang, Y. Huang et al., "Hepatitis B virus nucleic acid testing in Chinese blood donors with normal and elevated alanine aminotransferase," Transfusion, vol. 51, no. 12, pp. 25882595.

[73] V. Canutti Jr., "Risco transfusional: metodologia e estudo," Atualizacão em Hemoterapia, vol. 5, no. 1, pp. 90-99, 1998.

[74] E. J. Kupek, "Residual transfusion risk for hepatitis B and C in southern Brazil, 1991-1999," Journal of Viral Hepatitis, vol. 8, no. 1, pp. 78-82, 2001.

[75] E. Kupek, "Transfusion risk for hepatitis B, hepatitis C and HIV in the state of Santa Catarina, Brazil, 1991-2001," The Brazilian Journal of Infectious Diseases, vol. 8, no. 3, pp. 236-240, 2004.

[76] T. T. Goncalez, E. C. Sabino, E. L. Murphy, S. Chen, D. A. F. Chamone, and W. McFarland, "Human immunodeficiency virus test-seeking motivation in blood donors, São Paulo, Brazil," Vox Sanguinis, vol. 90, no. 3, pp. 170-176, 2006.

[77] C. Maresch, P. J. Schluter, A. D. Wilson, and A. Sleigh, "Residual infectious disease risk in screened blood transfusion from a high-prevalence population: santa Catarina, Brazil," Transfusion, vol. 48, no. 2, pp. 273-281, 2008.

[78] G. B. Schreiber, M. P. Busch, S. H. Kleinman, and J. J. Korelitz, "The risk of transfusion-transmitted viral infections," The New England Journal of Medicine, vol. 334, no. 26, pp. 1685-1690, 1996.

[79] R. Y. Dodd, E. P. Notari IV, and S. L. Stramer, "Current prevalence and incidence of infectious disease markers and estimated window-period risk in the American Red Cross blood donor population," Transfusion, vol. 42, no. 8, pp. 975979, 2002.

[80] S. A. Glynn, S. H. Kleinman, D. J. Wright, and M. P. Busch, "International application of the incidence rate/window period model," Transfusion, vol. 42, no. 8, pp. 966-972, 2002.

[81] S. Laperche, M. Maniez, V. Barlet et al., "A revised method for estimating hepatitis $B$ virus transfusion residual risk based on antibody to hepatitis B core antigen incident cases," Transfusion, vol. 48, no. 11, pp. 2308-2314, 2008.

[82] S. A. Glynn, M. P. Busch, G. B. Schreiber et al., "Effect of a national disaster on blood supply and safety: the September 11 experience," Journal of the American Medical Association, vol. 289, no. 17, pp. 2246-2253, 2003.

[83] R. Biswas, M. P. Busch, C. Hsia et al., "Comparative sensitivity of HBV NAT and HBsAg donor testing," Transfusion, vol. 4, Supplement, p. 8S, 2001.

[84] S. L. Stramer, J. P. Brodsky, S. Preston et al., "Comparative sensitivity of HBsAg and HBV NAT," Transfusion, vol. 4, Supplement, p. 8S.

[85] S. Zou, S. L. Stramer, E. P. Notari, F. Musavi, C. T. Fang, and R. Y. Dodd, "Estimating current incidence and residual risk of hepatitis B viral infection among blood donors in United States through a novel approach," Vox Sanguinis, vol. 95, supplement 1, pp. S22-S23, 2008.

[86] M. P. Busch, S. A. Glynn, S. L. Stramer et al., "A new strategy for estimating risks of transfusion-transmitted viral infections based on rates of detection of recently infected donors," Transfusion, vol. 45, no. 2, pp. 254-264, 2005.

[87] StataCorp, Stata Statistical Software: Release 9, StataCorp LP, College Station, Tex, USA, 2005.

[88] S. H. Kleinman, M. C. Kuhns, D. S. Todd et al., "Frequency of HBV DNA detection in US blood donors testing positive for the presence of anti-HBc: implications for transfusion transmission and donor screening," Transfusion, vol. 43, no. 6, pp. 696-704, 2003.

[89] M. P. Busch, "Should HBV DNA NAT replace HBsAg and/or anti-HBc screening of blood donors?" Transfusion Clinique Et Biologique, vol. 11, no. 1, pp. 26-32, 2004.

[90] M. C. Kuhns and M. P. Busch, "New strategies for blood donor screening for hepatitis B virus: nucleic acid testing versus immunoassay methods," Molecular Diagnosis and Therapy, vol. 10, no. 2, pp. 77-91, 2006.

[91] M. C. Kuhns, S. H. Kleinman, A. L. McNamara et al., "Lack of correlation between HBsAg and HBV DNA levels in blood donors who test positive for $\mathrm{HBsAg}$ and anti-HBc: implications for future HBV screening policy," Transfusion, vol. 44, no. 9, pp. 1332-1339, 2004.

[92] S. Linauts, J. Saldanha, and D. M. Strong, "PRISM hepatitis B surface antigen detection of hepatits B virus minipool nucleic acid testing yield samples," Transfusion, vol. 48, no. 7, pp. 13761382,2008

[93] S. H. Kleinman, D. M. Strong, G. G. E. Tegtmeier et al., "Hepatitis B virus (HBV) DNA screening of blood donations in minipools with the COBAS AmpliScreen HBV test," Transfusion, vol. 45, no. 8, pp. 1247-1257, 2005.

[94] C. Niederhauser, "Reducing the risk of hepatitis B virus transfusion-transmitted infection," Journal of Blood Medicine, vol. 2, pp. 91-102, 2011.

[95] J. Weusten, M. Vermeulen, H. van Drimmelen, and N. Lelie, "Refinement of a viral transmission risk model for blood donations in seroconversion window phase screened by nucleic 
acid testing in different pool sizes and repeat test algorithms," Transfusion, vol. 51, no. 1, pp. 203-215, 2011.

[96] R. Taira, M. Satake, S. Momose et al., "Residual risk of transfusion-transmitted hepatitis B virus (HBV) infection caused by blood components derived from donors with occult HBV infection in Japan," Transfusion, 2012.

[97] M. F. Yuen, D. K. Wong, C. K. Lee et al., "Transmissibility of hepatitis $\mathrm{B}$ virus (HBV) infection through blood transfusion from blood donors with occult HBV infection," Clinical Infectious Diseases, vol. 52, no. 5, pp. 624-632, 2011.

[98] Y. Chen, L. Li, Z. Zhou, N. Wang, C. Y. Zhang, and K. Zen, "A pilot study of serum microRNA signatures as a novel biomarker for occult hepatitis B virus infection," Medical Microbiology and Immunology, vol. 201, no. 3, pp. 389-395, 2012.

[99] A. A. Abdo, A. M. Abdou, U. S. Akarca et al., "A review of chronic hepatitis B epidemiology and management issues in selected countries in the Middle East," Journal of Viral Hepatitis, vol. 19, no. 1, pp. 9-22, 2012.

[100] S. H. Kleinman, N. Lelie, and M. P. Busch, "Infectivity of human immunodeficiency virus-1, hepatitis $\mathrm{C}$ virus, and hepatitis $\mathrm{B}$ virus and risk of transmission by transfusion," Transfusion, vol. 49, no. 11, pp. 2454-2489, 2009.

[101] B. Wang, G. B. Schreiber, S. A. Glynn et al., "Does prevalence of transfusion-transmissible viral infection reflect corresponding incidence in United States blood donors?” Transfusion, vol. 45, no. 7, pp. 1089-1096, 2005. 


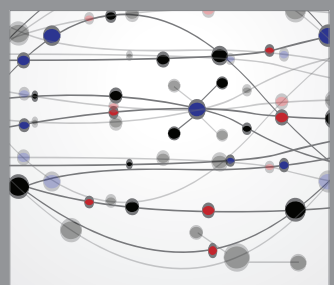

The Scientific World Journal
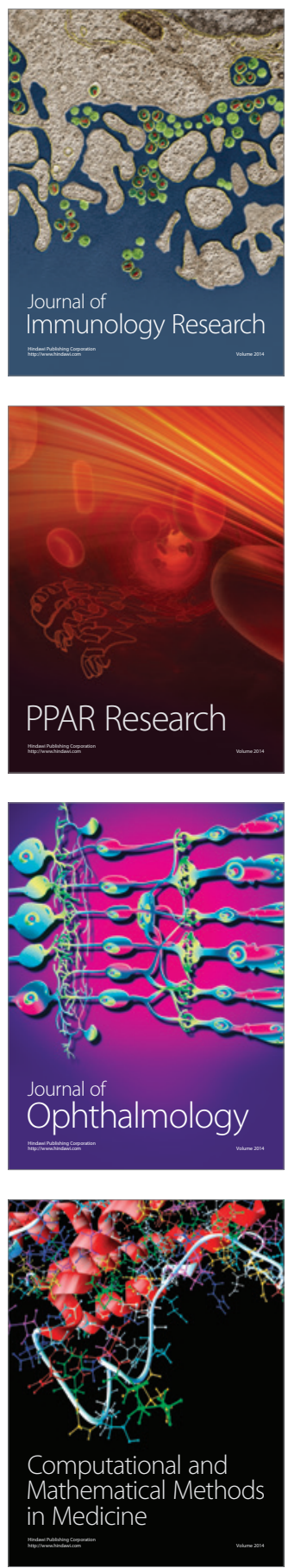

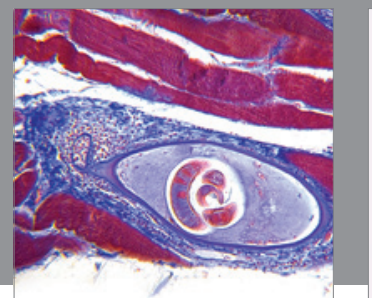

Gastroenterology

Research and Practice
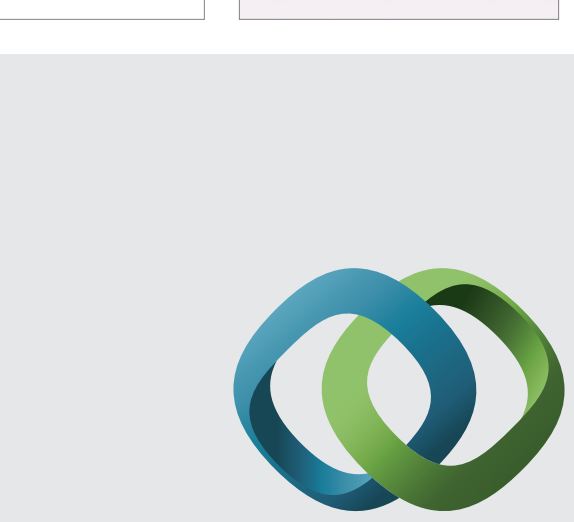

\section{Hindawi}

Submit your manuscripts at

http://www.hindawi.com
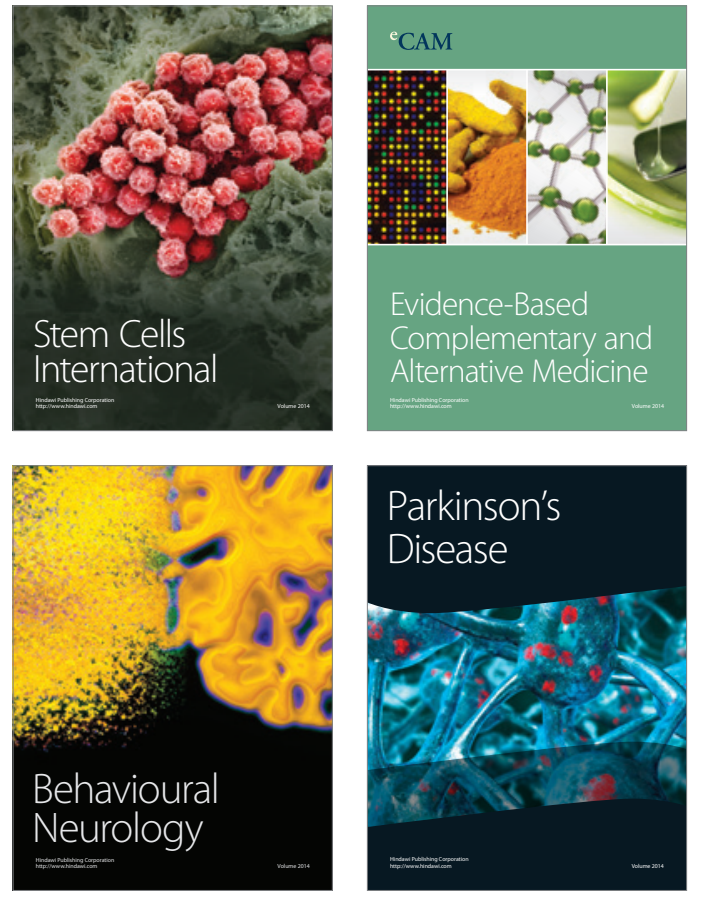
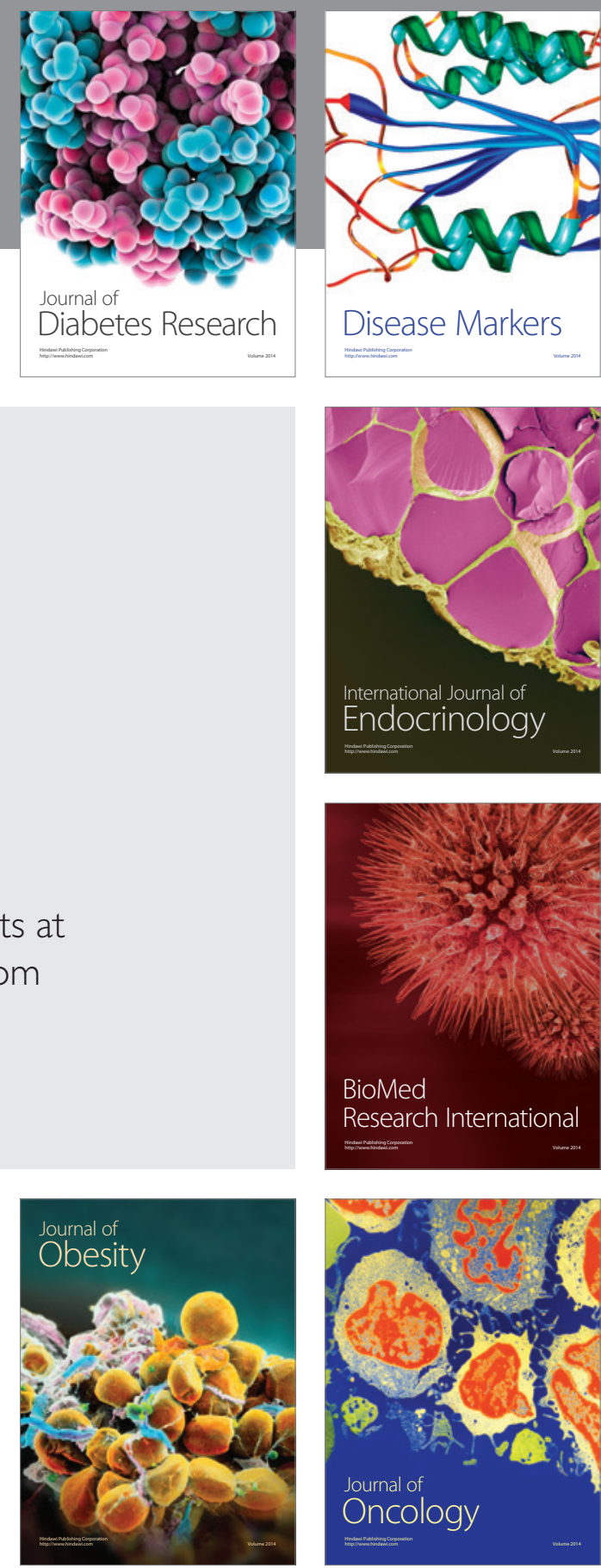

Disease Markers
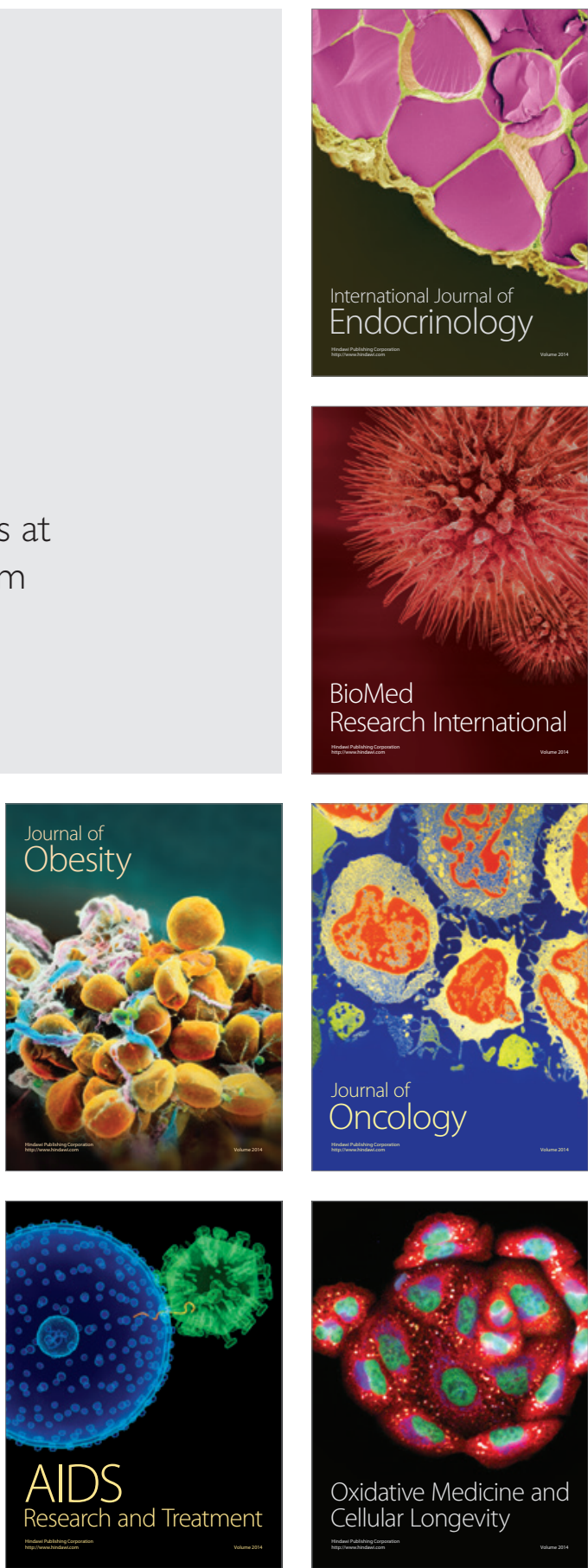